\title{
TEOREMA VALIDASI APROKSIMASI VARIASIONAL PADA PERSAMAAN SCHRÖDINGER NONLINIER DISKRIT
}

\author{
RISKI KURNIAWAN, MAHDHIVAN SYAFWAN, HARIPAMYU \\ Program Studi S1 Matematika, \\ Fakultas Matematika dan Ilmu Pengetahuan Alam, Universitas Andalas, \\ Kampus UNAND Limau Manis Padang, Indonesia. \\ email : riskikurniawanris@gmail.com
}

Diterima 9 Maret 2019 Direvisi 7 April 2019 Dipublikasikan 7 Mei 2019

\begin{abstract}
Abstrak. Aproksimasi variasional merupakan salah satu metode untuk menghampiri solusi soliton pada sistem nonlinier. Validasi aproksimasi variasional dalam menghampiri solusi soliton diskrit stasioner pada persamaan Schrödinger nonlinier diskrit dengan konstanta pengikat yang kecil dijustifikasi dengan menggunakan beberapa konsep analisis fungsional pada ruang barisan $l^{2}(\mathbb{Z})$. Konsep-konsep tersebut meliputi operator linier, pemetaan Lipschitz dan teorema titik tetap Banach. Hasil validasi aproksimasi variasional untuk soliton onsite menunjukkan bahwa aproksimasi variasional sangat baik dalam menghampiri solusi yang diselesaikan secara numerik untuk konstanta pengikat yang semakin kecil.
\end{abstract}

Kata Kunci: Aproksimasi Variasional, Persamaan Schrödinger Nonlinier Diskrit, Analisis Fungsional

\section{Pendahuluan}

Persamaan Schrödinger nonlinier diskrit (SNLD) merupakan salah satu persamaan beda-diferensial (difference-differential) yang sering dipelajari karena persamaan ini mendeskripsikan banyak fenomena penting dalam berbagai aplikasi. Contohnya yaitu dalam memodelkan dinamika kondensasi Bose-Einstein [Bose-Einstein Condensation (BEC)] yang terperangkap dalam potensial periodik. BEC sendiri merupakan wujud zat yang didinginkan sampai suhu mendekati $0^{\circ}$ Kelvin [7].

Salah satu hal yang sangat menarik dari persamaan SNLD ini adalah eksistensi solusi soliton yang dimilikinya. Soliton merupakan gelombang yang memiliki sifat dapat mempertahankan bentuknya dan merambat pada kecepatan konstan [2].

Persamaan SNLD dengan kenonlinieran kubik diberikan oleh

$$
i \dot{u}_{n}+\left|u_{n}\right|^{2} u_{n}=-\epsilon\left(u_{n+1}-2 u_{n}+u_{n-1}\right),
$$

dengan $u_{n} \equiv u_{n}(t) \in \mathbb{C}$ adalah fungsi gelombang diskrit pada waktu $t \in \mathbb{R}^{+}$dan site $n \in \mathbb{Z}, \dot{u}_{n}$ menyatakan turunan fungsi $u_{n}$ terhadap $t, \epsilon$ merepresentasikan konstanta pengingat (coupling constant) antara dua site yang bersebelahan. 
Persamaan SNLD dengan kenonlinieran kubik (1.1) dikenal sebagai persamaan yang tidak dapat diselesaikan secara eksak (non-integrable) [6]. Untuk menentukan hampiran solusi suatu persamaan beda-diferensial yang non-integrable, pendekatan analitik yang dapat digunakan salah satunya dengan metode aproksimasi variasional (selanjutnya disingkat AV). Metode ini diformulasi berdasarkan prinsip aksi terkecil (least action) atau dikenal juga dengan prinsip Hamiltonian. Prinsip ini menyatakan bahwa persamaan gerak suatu sistem ditentukan oleh titik-titik kritis dari aksi (yaitu integral waktu dari Lagrangian) sehingga diperoleh persamaan Euler-Lagrange untuk sistem tersebut [5]. Keberhasilan metode ini sangat bergantung pada fungsi penduga (ansatz) yang digunakan dalam menghampiri solusi yang diinginkan.

Hasil-hasil dari metode AV yang diperoleh selama ini diperiksa validasinya melalui perbandingan dengan solusi numerik untuk beberapa nilai parameter tertentu. Pada makalah ini, akan dibahas validasi dari metode AV pada solusi soliton SNLD dengan kenonlinieran kubik (1.1) secara umum. Justifikasi validasi AV pada persamaan SNLD dengan kenonlinieran kubik (1.1) telah diformulasi oleh Chong dkk [1] dalam sebuah lema yang dapat dijadikan sebagai ukuran validasi AV secara tepat.

Pada makalah ini, justifikasi AV stasioner yang diformulasi oleh Chong dkk [1] dibahas kembali dalam sebuah teorema. Teorema tersebut kemudian dibuktikan lebih detail dengan menggunakan beberapa konsep pada analisis fungsional.

\section{Aproksimasi Variasional dan Beberapa Konsep Analisis Fungsional}

Solusi soliton diskrit stasioner dari persamaan (1.1) ditentukan dengan menggunakan transformasi $u_{n}(t)=\psi_{n} e^{i(1-2 \epsilon) t}$, sehingga diperoleh

$$
\psi_{n}^{3}-\psi_{n}=-\epsilon\left(\psi_{n-1}+\psi_{n+1}\right) .
$$

Untuk menentukan hampiran solusi soliton stasioner dari persamaan (2.1), digunakan metode AV. Berikut langkah-langkah sistematis dari metode AV [4] :

(1) Rumuskan Lagrangian dari persamaan yang akan ditinjau.

(2) Pilih sebuah fungsi penduga (ansatz) yang sesuai dan memuat sejumlah hingga parameter (disebut sebagai parameter variasional).

(3) Substitusikan ansatz yang dipilih ke Lagrangian dan selesaikan penjumlahannya (untuk sistem diskrit) atau integrasinya (untuk sistem kontinu).

(4) Tentukan titik-titik kritis untuk parameter variasional dengan menyelesaikan persamaan Euler-Lagrange.

Justifikasi validasi AV pada solusi soliton stasioner persamaan SNLD (2.1) menggunakan beberapa konsep analisis fungsional pada ruang barisan $l^{2}(\mathbb{Z})$. Berikut diberikan beberapa konsep tersebut.

Definisi 2.1. [3] Operator linier $T$ adalah suatu operator sedemikian sehingga un- 
284 Riski Kurniawan dkk

tuk setiap $x, y \in \mathfrak{D}(T)$ dan skalar $\alpha$, berlaku :

$$
\begin{aligned}
T(x+y) & =T x+T y, \quad \text { dan } \\
T(\alpha x) & =\alpha T x .
\end{aligned}
$$

Definisi 2.2. [3] Misalkan $X$ dan $Y$ ruang norm dan $T: \mathfrak{D}(T) \longrightarrow Y$ suatu operator linier, dengan $\mathfrak{D}(T) \subset X$. Operator $T$ dikatakan terbatas jika terdapat bilangan riil $c$ sedemikian sehingga untuk semua $x \in \mathfrak{D}(T)$ berlaku

$$
\|T x\| \leq c\|x\| .
$$

Definisi 2.3. [3] Misalkan $X=(X, d)$ suatu ruang metrik. Pemetaan $T: X \longrightarrow X$ dikatakan pemetaan Lipschitz jika terdapat konstanta $\alpha>0$, sedemikian sehingga untuk setiap $x, y \in X$ berlaku

$$
d(T x, T y) \leq \alpha d(x, y)
$$

Infimum dari semua kemungkinan nilai $\alpha$ disebut dengan konstanta Lipschitz dari T. Jika konstanta Lipschitz kecil dari 1, maka T dikatakan suatu kontraksi.

Teorema 2.4. (Teorema Titik Tetap Banach) [3]. Misalkan suatu ruang metrik $X=(X, d)$ lengkap, dengan $X \neq \varnothing$ dan $T: X \longrightarrow X$ suatu kontraksi pada $X$, maka $T$ mempunyai tepat satu titik tetap.

Diberikan matriks persegi $A=\left(a_{i j}\right)$ dengan $n$ baris. Konsep nilai eigen dan vektor eigen didefinisikan dari persamaan

$$
A x=\lambda x,
$$

berdasarkan definisi berikut.

Definisi 2.5. [3] Nilai eigen dari matriks persegi $A=\left(a_{i j}\right)$ adalah bilangan $\lambda$ sedemikian sehingga (2.4) mempunyai solusi $x \neq 0$. Nilai $x$ ini disebut vektor eigen dari A yang berkaitan dengan nilai eigen $\lambda$. Semua vektor eigen yang berkaitan dengan nilai eigen $\lambda$ dan vektor nol membentuk suatu ruang vektor yang disebut ruang eigen dari $A$ berkaitan dengan nilai eigen $\lambda$. Himpunan $\sigma(A)$ dari semua nilai eigen $A$ disebut spektrum dari $A$.

Lema 2.6. Misalkan $X$ suatu ruang norm dan $T: X \longrightarrow X$ adalah operator linier dengan $T x=A x$ untuk setiap $x \in X$ dan suatu matriks persegi A. Jika $\sigma(A)$ spektrum dari $A$, maka operator $T^{-1}$ ada jika dan hanya jika $0 \notin \sigma(A)$.

Bukti. Nilai eigen $\lambda$ dari matriks $A$ adalah solusi persamaan $|A-\lambda I|=0$. Untuk menunjukkan keberadaan $T^{-1}$ cukup dengan menunjukkan $A^{-1}$ ada.

Misalkan terdapat $\lambda_{i}=0$ untuk suatu $i \in \mathbb{N}$, maka $|A|=0$, akibatnya $A^{-1}$ tidak ada. Di sisi lain, misalkan $\lambda_{i} \neq 0$ untuk setiap $i=1,2, \cdots$, sehingga 0 bukan solusi dari $|A-\lambda I|=0$, maka $|A| \neq 0$, akibatnya $A^{-1}$ ada.

Lema 2.7. Misalkan $X$ suatu ruang norm dan $T: X \longrightarrow X$ adalah operator linier dengan $T x=A x$ untuk setiap $x \in X$ dan suatu matriks persegi A. Jika $\sigma(A)$ spektrum dari $A$, maka $T$ terbatas dan $\|T\|=\operatorname{maks}\left\{\left|k_{i}\right|: k_{i} \in \sigma(A)\right\}$. 
Bukti. Misalkan $k_{i}$ sebarang nilai eigen dari $A$ dan $x \in X$ sebarang. Karena $X$ ruang norm, maka $\|T x\|=\left|k_{i}\right|\|x\|$. Dapat dipilih konstanta $c=$ maks $\left\{\left|k_{i}\right|: k_{i} \in\right.$ $\sigma(A)\}$ sedemikian sehingga $\|T x\| \leq c\|x\|$ untuk setiap $x \in X$. Selanjutnya diperoleh

$$
\|T\|=\sup _{x \in X \backslash\{0\}} \frac{\|T x\|}{\|x\|}=\operatorname{maks}\left\{\left|k_{i}\right|: k_{i} \in \sigma(A)\right\} .
$$

\section{Pembahasan}

Pada bab ini akan dibahas justifikasi aproksimasi variasional stasioner. Sebelum itu, diberikan beberapa lema berikut.

Lema 3.1. Jika $\alpha=\left(\alpha_{i}\right)$ dan $\beta=\left(\beta_{i}\right) \in l^{2}(\mathbb{Z})$ dan didefinisikan $\alpha \beta=\left(\alpha_{i} \beta_{i}\right)$, maka $\|\alpha \beta\|_{l^{2}} \leq\|\alpha\|_{l^{2}}\|\beta\|_{l^{2}}$.

Bukti. Berdasarkan ketaksamaan Cauchy-Schwarz, diperoleh

$$
\sqrt{\sum_{n \in \mathbb{Z}}\left|\alpha_{i} \beta_{i}\right|^{2}} \leq \sqrt{\sum_{n \in \mathbb{Z}}\left|\alpha_{j}\right|^{2}} \sqrt{\sum_{n \in \mathbb{Z}}\left|\beta_{k}\right|^{2}},
$$

atau $\|\alpha \beta\|_{l^{2}} \leq\|\alpha\|_{l^{2}}\|\beta\|_{l^{2}}$.

Lema 3.2. Jika $L: l^{2}(\mathbb{Z}) \longrightarrow l^{2}(\mathbb{Z})$ suatu operator yang didefinisikan oleh

$$
(L \varphi)_{n}=\left(1-3 \psi_{* n}^{2}\right) \varphi_{n}-\epsilon\left(\varphi_{n+1}+\varphi_{n-1}\right),
$$

maka L terbatas.

Bukti. Ambil $\varphi=\left(\varphi_{n}\right) \in l^{2}(\mathbb{Z})$ sebarang. Berdasarkan ketaksamaan segitiga dan Lema 2.7 diperoleh

$$
\begin{aligned}
\|L \varphi\|_{l^{2}} & \leq \operatorname{maks}\left\{\left|1-3 \psi_{* n}^{2}\right|\right\}\|\varphi\|_{l^{2}}+\epsilon\left\|\left(\varphi_{n-1}\right)\right\|_{l^{2}}+\epsilon\left\|\left(\varphi_{n+1}\right)\right\|_{l^{2}} \\
& =2(1+\epsilon)\|\varphi\|_{l^{2}} .
\end{aligned}
$$

Pilih konstanta $c=2(1+\epsilon)$ sedemikian sehingga berlaku $\|L \varphi\|_{l^{2}} \leq c\|\varphi\|_{l^{2}}$.

Lema 3.3. Misalkan $N(\varphi): l^{2}(\mathbb{Z}) \rightarrow l^{2}(\mathbb{Z})$ adalah pemetaan pada bola $B_{\delta} \subset l^{2}(\mathbb{Z})$ dengan jari-jari $\delta>0$ berpusat di 0 yang didefinisikan oleh $N_{n}(\varphi)=3 \psi_{* n} \varphi_{n}^{2}+\varphi_{n}^{3}$, maka $N$ adalah pemetaan Lipschitz, khususnya terdapat konstanta $C_{\delta}, D_{\delta}>0$ yang bergantung pada $\delta>0$ sedemikian sehingga untuk setiap $\varphi, \varphi^{\prime} \in B_{\delta}$ berlaku

$$
\|N(\varphi)\|_{l^{2}} \leq C_{\delta}\|\varphi\|_{l^{2}}^{2},
$$

dan

$$
\left\|N(\varphi)-N\left(\varphi^{\prime}\right)\right\|_{l^{2}} \leq D_{\delta}\left(\|\varphi\|_{l^{2}}+\left\|\varphi^{\prime}\right\|_{l^{2}}\right)\left\|\varphi-\varphi^{\prime}\right\|_{l^{2}} .
$$

Bukti. Ambil sebarang $\varphi, \varphi^{\prime} \in B_{\delta}$. Akibatnya $\|\varphi\|_{l^{2}},\left\|\varphi^{\prime}\right\|_{l^{2}} \leq \delta$. Berdasarkan ketaksamaan segitiga, Lema 2.7 dan Lema 3.1 diperoleh

$$
\begin{aligned}
\|N(\varphi)\|_{l^{2}} & \leq \operatorname{maks}\left\{\left|3 \psi_{* n}\right|\right\}\|\varphi\|_{l^{2}}^{2}+\|\varphi\|_{l^{2}}\|\varphi\|_{l^{2}}^{2} \\
& \leq(3+\delta)\|\varphi\|_{l^{2}}^{2} .
\end{aligned}
$$


dan

$$
\begin{aligned}
\left\|N(\varphi)-N\left(\varphi^{\prime}\right)\right\|_{l^{2}} \leq & \operatorname{maks}\left\{\left|3 \psi_{* n}\right|\right\}\|\varphi-\varphi\|_{l^{2}}\left\|\varphi+\varphi^{\prime}\right\|_{l^{2}} \\
& +\left\|\varphi-\varphi^{\prime}\right\|_{l^{2}}\left\|\varphi^{2}+\varphi \varphi^{\prime}+\varphi^{\prime 2}\right\|_{l^{2}} \\
\leq & (3+2 \delta)\left(\|\varphi\|_{l^{2}}+\left\|\varphi^{\prime}\right\|_{l^{2}}\right)\left\|\varphi-\varphi^{\prime}\right\|_{l^{2}}
\end{aligned}
$$

Pilih $C_{\delta}=3+\delta$ dan $D_{\delta}=3+2 \delta$ sedemikian sehingga (3.2) dan (3.3) terpenuhi.

Untuk $\epsilon=0$, persamaan (3.1) dapat ditulis sebagai

$$
(L \varphi)_{n}=\left(1-3 \psi_{* n}^{2}\right) \varphi_{n}
$$

Jika $L^{-1}$ ada, maka berdasarkan Lema 2.7 diperoleh

$$
\left\|L^{-1}\right\|_{l^{2}}=\operatorname{maks}\left\{\frac{1}{\left|1-3 \psi_{* n}^{2}\right|}\right\}=1 .
$$

Akibatnya, $\left\|L^{-1}\right\|_{l^{2}}=1$ untuk setiap $\epsilon>0$ yang kecil.

Didefinisikan residual dari persamaan SNLD stasioner (2.1) sebagai

$$
R_{n}(\psi)=\psi_{n}^{3}-\psi_{n}+\epsilon\left(\psi_{n-1}+\psi_{n+1}\right) .
$$

Selanjutnya, didefinisikan operator $A$ yang diberikan oleh

$$
A(\varphi):=L^{-1} R\left(\psi_{*}\right)+L^{-1} N(\varphi),
$$

dengan $\psi_{*}$ adalah solusi aproksimasi dari $\psi$. Operator $A$ didefinisikan pada (3.7) merupakan kontraksi, yaitu berdasarkan lema berikut.

Lema 3.4. Jika operator $A: B_{\delta} \rightarrow B_{\delta}$ didefinisikan pada (3.7) dengan $L$ diberikan oleh (3.1), maka $A$ adalah suatu kontraksi untuk suatu $\delta=\mathcal{O}\left(\epsilon^{p}\right)$.

Bukti. Ambil $\varphi, \varphi^{\prime} \in B_{\delta}$ sebarang. Karena $\left\|L^{-1}\right\|_{l^{2}}=1$, maka berdasarkan Lema 3.3 diperoleh

$$
\begin{aligned}
\left\|A(\varphi)-A\left(\varphi^{\prime}\right)\right\|_{l^{2}} & \leq\left\|L^{-1}\left(R\left(\psi_{*}\right)-R\left(\psi_{*}\right)\right)\right\|_{l^{2}}+\left\|L^{-1}\left(N(\varphi)-N\left(\varphi^{\prime}\right)\right)\right\|_{l^{2}} \\
& \leq\left\|L^{-1}\right\|_{l^{2}}\left(\left\|N(\varphi)-N\left(\varphi^{\prime}\right)\right\|_{l^{2}}\right) \\
& \leq D_{\delta}\left(\|\varphi\|_{l^{2}}+\left\|\varphi^{\prime}\right\|_{l^{2}}\right)\left\|\varphi-\varphi^{\prime}\right\|_{l^{2}} \\
& \leq 2 D_{\delta} \delta\left\|\varphi-\varphi^{\prime}\right\|_{l^{2}} .
\end{aligned}
$$

Karena $\delta=\mathcal{O}\left(\epsilon^{p}\right)$ bilangan positif yang sangat kecil, maka konstanta $2 D_{\delta} \delta$ juga akan sangat kecil. Akibatnya, $\inf \left\{2 D_{\delta} \delta\right\} \leq 1$. Berdasarkan Definisi 2.3, maka terbukti bahwa $A$ suatu kontraksi.

Selanjutnya diberikan justifikasi aproksimasi variasional untuk persamaan SNLD stasioner (2.1) dengan $\epsilon>0$ yang kecil sesuai dengan teorema berikut ini.

Teorema 3.5. [1] Misalkan $\psi_{*}$ adalah solusi hampiran dari persamaan SNLD stasioner (2.1) sedemikian sehingga

$$
\left\|R\left(\psi_{*}\right)\right\|_{l^{2}}=\mathcal{O}\left(\epsilon^{p}\right) \text { ketika } \epsilon \rightarrow 0
$$


untuk suatu $p>0$ dan terdapat suatu himpunan berhingga $S \subset \mathbb{Z}$ dan suatu himpunan biner $\left\{\sigma_{n}\right\}_{n \in S}$ dengan $\sigma_{n} \in\{+1,-1\}$ sedemikian sehingga

$$
\lim _{\epsilon \rightarrow 0}\left\|\psi_{*}-\sum_{n \in S} \sigma_{n} e_{n}\right\|_{l^{2}}=0,
$$

dimana $e_{n}$ adalah vektor satuan pada site $n \in \mathbb{Z}$ di $l^{2}(\mathbb{Z})$. Maka, terdapat bilangan $\epsilon_{0}>0, C>0$ dan solusi tunggal persamaan $S N L D$ stasioner (2.1) dengan $\epsilon \in\left(0, \epsilon_{0}\right)$ sedemikian sehingga

$$
\left\|\psi-\psi_{*}\right\|_{l^{2}} \leq C \epsilon^{p}
$$

Bukti. Didefinisikan $\varphi$ sebagai selisih antara $\psi$ dan solusi hampiran $\psi_{*}$. Substitusikan $\psi=\psi_{*}+\varphi$ ke (2.1), diperoleh

$$
\left(1-3 \psi_{* n}^{2}\right) \varphi_{n}-\epsilon\left(\varphi_{n+1}+\varphi_{n-1}\right)=\psi_{* n}^{3}-\psi_{* n}+\epsilon\left(\psi_{* n+1}+\psi_{* n-1}\right)+3 \psi_{* n} \varphi_{n}^{2}+\varphi_{n}^{3} .
$$

Persamaan di atas dapat ditulis kembali sebagai

$$
L \varphi=R\left(\psi_{*}\right)+N(\varphi),
$$

dengan $R\left(\psi_{*}\right) \in l^{2}(\mathbb{Z})$ adalah residual (3.6), $L: l^{2}(\mathbb{Z}) \rightarrow l^{2}(\mathbb{Z})$ adalah operator terbatas berdasarkan Lema 3.2 dan $N(\varphi): l^{2}(\mathbb{Z}) \rightarrow l^{2}(\mathbb{Z})$ adalah pemetaan Lipschitz pada bola $B_{\delta} \subset l^{2}(\mathbb{Z})$ dengan jari-jari $\delta>0$ dan berpusat di 0 berdasarkan Lema 3.3 .

Kondisi (3.9) mengakibatkan $\left(1-3 \psi_{* n}^{2}\right)$ mendekati -2 atau 1. Selanjutnya, pada $\epsilon=0,(L \varphi)_{n}=\varphi_{n}$ atau $(L \varphi)_{n}=-2 \varphi_{n}$ yang menunjukkan bahwa spektrum $L$ pada $\epsilon=0$ hanya memuat 1 atau -2 . Karena spektrum $L$ pada $\epsilon=0$ tidak memuat nol atau bilangan yang dekat ke nol, maka berdasarkan Lema 2.6, operator $L$ mempunyai invers untuk setiap $\epsilon>0$ yang kecil dengan $\left\|L^{-1}\right\|_{l^{2}}=1$. Akibatnya, persamaan (3.11) dapat ditulis sebagai operator $A$ yang diberikan pada (3.7)

Berdasarkan Lema 3.4 diketahui operator $A$ yaitu $A(\varphi)=\varphi$ suatu kontraksi. Selanjutnya berdasarkan Teorema 2.4 (Teorema Titik Tetap Banach), operator $A$ mempunyai tepat satu titik tetap. Karena $\left\|L^{-1}\right\|_{l^{2}}=1$, maka berdasarkan Lema 3.3 diperoleh

$$
\begin{aligned}
\|\varphi\|_{l^{2}} & \leq\left\|L^{-1}\right\|_{l^{2}}\left(\left\|R\left(\psi_{*}\right)\right\|_{l^{2}}+\|N(\varphi)\|_{l^{2}}\right) \\
& \leq \delta+C_{\delta}\|\varphi\|_{l^{2}}^{2} \\
& \leq \delta+C_{\delta} \delta^{2} \\
& =\left(\delta^{1 / p}\right)^{p}\left(1+C_{\delta} \delta\right) .
\end{aligned}
$$

Jadi, dapat dipilih $\epsilon_{0}=\delta^{1 / p}, C=1+C_{\delta} \delta>0$ dan karena $\varphi=\psi-\psi_{*}$, maka terdapat solusi tunggal persamaan SNLD stasioner (2.1) dengan $\epsilon \in\left(0, \epsilon_{0}\right)$ sedemikian sehingga pertidaksamaan (3.10) terpenuhi. Akibatnya, Teorema 3.5 terbukti.

Selanjutnya, akan diturunkan AV untuk soliton onsite pada persamaan (2.1). Sebagai langkah pertama dalam metode AV, rumuskan terlebih dahulu Lagrangian 
dari persamaan (2.1) yaitu diberikan oleh

$$
\mathcal{L}(\psi)=\sum_{n \in \mathbb{Z}}\left[\frac{1}{2} \psi_{n}^{4}-\psi_{n}^{2}+2 \epsilon \psi_{n} \psi_{n+1}\right] .
$$

Langkah berikutnya adalah memilih ansatz yang sesuai, yaitu diberikan oleh

$$
\psi_{* n}=A e^{-\eta|n|}, \quad n \in \mathbb{Z} .
$$

dengan parameter $A$ dan $\eta \in \mathbb{R}_{+}$yang akan dicari nilainya.

Karena $\psi_{n} \rightarrow 0$ untuk $n \rightarrow \infty$, maka suku $\psi_{n}^{3}$ pada (2.1) dapat diabaikan. Akibatnya, persamaan (2.1) dapat dipandang sebagai

$$
-\psi_{n}=-\epsilon\left(\psi_{n+1}+\psi_{n-1}\right) \text {. }
$$

Dengan mensubstitusikan ansatz (3.13) ke (3.14) diperoleh nilai $\eta$ yang bergantung pada $\epsilon$, yaitu berdasarkan hubungan

$$
1=\epsilon\left(e^{\eta}+e^{-\eta}\right) \Rightarrow \eta=\operatorname{arccosh}\left(\frac{1}{2 \epsilon}\right) .
$$

Ekspansi Taylor dari $e^{-\eta}$ di sekitar $\epsilon=0$ diberikan oleh

$$
e^{-\eta}=\epsilon+\epsilon^{3}+\mathcal{O}\left(\epsilon^{5}\right)
$$

Substitusikan ansatz (3.13) ke Lagrangian (3.12), dengan menghitung jumlahnya dan menggunakan persamaan (3.15), diperoleh Lagrangian efektif

$$
\begin{aligned}
\mathcal{L}_{\text {eff }}(A) & =\frac{1}{2} A^{4} \operatorname{coth}(2 \eta)-A^{2} \operatorname{coth}(\eta)+2 \epsilon A^{2} \operatorname{csch}(\eta) \\
& =\frac{1}{2} A^{4} \operatorname{coth}(2 \eta)+A^{2}\left(2 \epsilon e^{-\eta}-1\right) .
\end{aligned}
$$

Selanjutnya akan ditentukan titik-titik kritis untuk parameter $A$ dengan menyelesaikan persamaan Euler-Lagrange yaitu $\frac{\partial \mathcal{L}_{\text {eff }}}{\partial A}=0$.

$$
\frac{\partial \mathcal{L}_{\text {eff }}}{\partial A}=2 A\left(A^{2} \operatorname{coth}(2 \eta)-\left(1-2 \epsilon e^{-\eta}\right)\right)=0 .
$$

Akibatnya, $A=0$ (solusi nol) atau

$$
A=\sqrt{\left(1-2 \epsilon e^{-\eta}\right) \tanh (2 \eta)}=1-\epsilon^{2}+\mathcal{O}\left(\epsilon^{4}\right) .
$$

Residual (3.6) yang dievaluasi untuk ansatz (3.13) diberikan oleh

$$
R_{n}\left(\psi_{*}\right)=\left\{\begin{array}{cc}
A\left(A^{2}-1+2 \epsilon e^{-\eta}\right), & n=0, \\
A^{3} e^{-3 \eta|n|}, & |n| \in \mathbb{N} .
\end{array}\right.
$$

Dengan mensubstitusikan persamaan (3.16) dan (3.18) ke persamaan di atas, maka diperoleh

$$
R_{0}\left(\psi_{*}\right)=\left(1-\epsilon^{2}+\mathcal{O}\left(\epsilon^{4}\right)\right)\left(-2 \epsilon^{2}+\mathcal{O}\left(\epsilon^{4}\right)+2 \epsilon\left(\epsilon+\epsilon^{3}+\mathcal{O}\left(\epsilon^{5}\right)\right)=\mathcal{O}\left(\epsilon^{4}\right),\right.
$$

dan

$$
R_{n}\left(\psi_{*}\right)=\left(1-\epsilon^{2}+\mathcal{O}\left(\epsilon^{4}\right)\right)^{3}\left(\epsilon+\epsilon^{3}+\mathcal{O}\left(\epsilon^{5}\right)\right)^{3|n|}=\mathcal{O}\left(\epsilon^{3|n|}\right), \quad|n| \in \mathbb{Z} .
$$

Akibatnya, $\left\|R\left(\psi_{*}\right)\right\|_{l^{2}}=\sqrt{\sum_{n \in \mathbb{Z}}\left[R_{n}\left(\psi_{*}\right)\right]^{2}}=\sqrt{\mathcal{O}\left(\epsilon^{6}\right)}=\mathcal{O}\left(\epsilon^{3}\right)$ saat $\epsilon \rightarrow 0$. 
Teorema 3.5 selanjutnya menghasilkan proposisi berikut ini untuk soliton onsite dengan ansatz (3.13).

Proposisi 3.6. [1] Misalkan $\eta$ dan A diberikan oleh (3.15) dan (3.18). Maka terdapat $\epsilon_{0}, C \geq 0$ sedemikian sehingga untuk semua $\epsilon \in\left(0, \epsilon_{0}\right)$ persamaan $S N L D$ stasioner (2.1) mempunyai solusi $\psi \in l^{2}(\mathbb{Z})$ dan memenuhi

$$
\left\|\psi-\psi^{(1)}\right\|_{l^{2}} \leq C \epsilon^{3} .
$$

Untuk memeriksa Proposisi 3.6, galat didefinisikan oleh $\left\|\psi-\psi_{*}\right\|_{l^{2}}$, dengan $\psi$ adalah solusi numerik dan $\psi_{*}$ adalah solusi variasional. Kemudian, galat yang diperoleh diplot terhadap $\epsilon$. Dengan menggunakan pencocokan kurva pada Matlab untuk kurva galat tersebut, diperoleh $f(\epsilon)=4,39 \epsilon^{3,25}$. Hal ini diperlihatkan pada Gambar 1. Perhatikan bahwa hasil ini memenuhi Proposisi 3.6. Dengan demikian dapat disimpulkan bahwa solusi AV untuk soliton onsite dengan menggunakan ansatz (3.13) adalah valid.

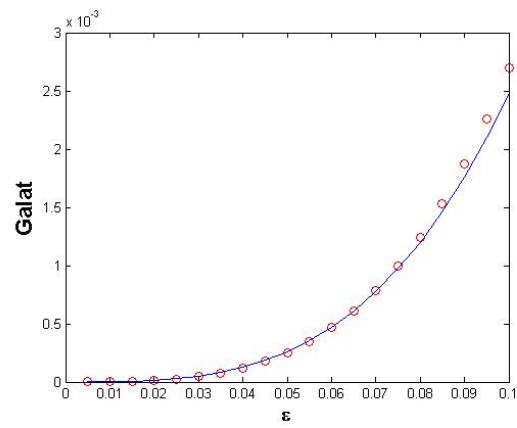

Gambar 1. Galat untuk soliton onsite dan fungsi $4,39 \epsilon^{3,25}$.

\section{Kesimpulan}

Pada tugas akhir ini, diberikan teorema yang memvalidasi aproksimasi variasional (AV) dalam menghampiri solusi soliton pada persamaan Schrödinger nonlinier diskrit. Teorema ini menggunakan beberapa konsep analisis fungsional pada ruang barisan $l^{2}(\mathbb{Z})$ seperti operator terbatas, pemetaan Lipschitz dan teorema titik tetap Banach. Selanjutnya, teorema tersebut digunakan untuk memvalidasi AV untuk soliton onsite. Hasil validasi yang diperoleh menunjukkan bahwa AV sangat baik dalam menghampiri solusi yang diselesaikan secara numerik.

\section{Ucapan Terima kasih}

Penulis mengucapkan terima kasih kepada Prof. Dr. Muhafzan, Dr. Yanita dan Izzati Rahmi HG, M.Si yang telah memberi masukan dan saran sehingga makalah ini dapat diselesaikan dengan baik. 
290 Riski Kurniawan dkk

\section{Daftar Pustaka}

[1] Chong, C., D.E. Pelinovsky and G. Schneider. 2011. On the validity of variational approximations in discrete nonlinear Schrödinger equation, Physica D. 241 : halaman 115-124.

[2] Drazin, P.G. 1989. Soliton: An Introduction. Cambridge University Press, Cambridge.

[3] E. Kreyszig. 1978. Introductory Functional Analysis with Applications. John Wiley and Sons, New York.

[4] Kaup. D. J and Vogel T. K. 2007. Quantitative Measurement of Variational Approximation, Phys. Lett. A 362 : halaman 289.

[5] Kevin W. Cassel. 2013. Variational Methods with Application in Science and Engineering. Cambridge, New York.

[6] Kevrekidis, P.G. 2009. Discrete Nonlinear Schrodinger Equation: Mathematical Analysis, Numerical Computations and Physical Perspectives. Springer, New York.

[7] Pelinovsky, D. E. 2011. Localization in Periodic Potentials: From Schrodinger Operators to the Gross-Pitaevskii Equation. Cambridge University Press, Cambridge. 